\title{
Valid name for the Pratt's leaf-nosed bat, Hipposideros pratti (Hipposideridae, Chiroptera, Mammalia)
}

\author{
Sergei V. Kruskop
}

\begin{abstract}
Leaf-nosed bat Phyllorhina swinhoei described by Peters in 1871 from the South-East China was traditionally treated as a synonym of Hipposideros armiger. The only exception was represented by short publication of Pohle, published in 1943, where he mentioned that the Ph. swinhoei type actually belongs to $H$. pratti - point of view not accepted by the later authors. Studying collections of the Berlin Zoological Museum, I have found that three specimens from the Ph. swinhoei type series belong to $H$. armiger, while two other, including the holotype, to $H$. pratti. Since the Peters' name is older, the species should be named H. swinhoei (Peters, 1871), and the whole species group should be renamed respectively.
\end{abstract}

KEY WORDS: Hipposideros armiger, Hipposideros pratti, South-East Asia, taxonomy, nomenclature.

Sergei V. Kruskop [kruskop@zmmu.msu.ru], Zoological Museum, Moscow State University, Bolshaya Nikitskaya stê. 6, Moscow 125009, Russia.

\section{Валидное название листоноса Пратта Hipposideros pratti (Hipposideridae, Chiroptera, Mammalia)}

\section{С.В. Крускоп}

РЕЗЮМЕ. Листоноса Phyllorhina swinhoei, описанного Петерсом в 1871 г. из юго-восточного Китая, традиционно включали в синонимику Hipposideros armiger. Исключение составляла краткая публикация Пола (Pohle) 1943 г., где он указал, что тип Ph. swinhoei на самом деле относится к $H$. pratti, и которая не была принята во внимание последующими авторами. Работая с коллекциями Берлинского зоологического музея, мы установили, что три экземпляра из типовой серии $P h$. swinhoei принадлежат к H. armiger, а два, включая голотип - к H. pratti. Поскольку название, данное Петерсом, старше, то вид должен называться H. swinhoei (Peters, 1871), и соответственно должна быть переименована и видовая группа.

КЛЮЧЕВЫЕ СЛОВА: Hipposideros armiger, Hipposideros pratti, Юго-Восточная Азия, систематика, номенклатура.

\section{Background}

The genus Hipposideros is one of the largest mammalian genera, containing no less than 70 living species distributed throughout Palaeotropics and Australia (Simmons, 2005). In this case, numerous unresolved taxonomic and nomenclature questions concerning this genus are quite predictable.

The "pratti" species group was stated by Tate (1941) for only two species: $H$. pratti and $H$. lylei. One additional species, H. scutinares, was recently described (Robinson et al., 2003). In the light of the genetic data species independence of this form is doubtful (Francis et al., 2010). According to Tate, group members are similar with another large South-East Asian Hipposideros, $H$. armiger, in general size and proportions of skull and teeth, though in $H$. pratti the cheek teeth are less robust than in $H$. armiger and skull possess wellpronounced frontal depression. Externally members of the "pratti" group are characterized by well-developed transverse lobate structures behind the nose leafs, espe- cially huge in adult males (Tate, 1941; Francis, 2008; Kruskop, 2013).

In 1871 Peters on the basis of five specimens, collected in Amoy (= Xiamen), Fujian Province, China, described a new species Phyllorhina swinhoei. However Peters himself supposed possible synonymy between his newly described form and Ph. (= Hipposideros) armiger and Dobson (1876) followed this opinion. Allen (1938) in his monograph on mammals of China and Mongolia considered $H$. swinhoei as a subspecies of $H$. armiger, distinct from the typical form. Allen definitely possessed collection material of $H$. armiger and $H$. pratti from China, but he presumably never saw any types of $H$. swinhoei (see Allen, 1938: 192). In 1941 Tate, making an observation of Hipposideros, wrote that he saw specimen of $H$. armiger from terra typica of $P h$. swinhoei and found no significant difference between it and $H$. armiger s. str.; thus he suggested to treat the name swinhoei Peters as a full synonym of $H$. $a$. armiger. It is noticeable, that the only Amoy animal seen by Tate was a mounted specimen with skull inside (Tate, 1941: 371). 
Two years later Pohle (1943) made an overview of the Peters' types and mentioned that the syntypes of $P$. swinhoei actually belong to Hipposideros pratti, not to $H$. armiger and that in this case the name "swinhoei Peters, 1871" has the priority against "pratti Thomas, 1891."

However, in subsequent publications this opinion was entirely ignored. Ellerman and Morrison-Scott (1951), following Allen's opinion, considered P. swinhoei as a subspecies of $H$. armiger. Hill (1963) in his revision of Hipposideros concurred with Tate, appealing to the own Peters' opinion. Hill and Smith (1992), Koopman (1994) and Simmons (2005) followed the Tate's point of view without any comments. Robinson (Robinson et al., 2003), while discussing content of the "H. pratti" species group, not mentioned $H$. swinhoei at all. Finally, Turni and Kock (2008), observing bat types in the collection of the Berlin Zoological Museum, uniquely attributed the type series of $P$. swinhoei to $H$. armiger, indicating that Pohle erroneously treated $P$. swinhoei as a senior synonym of $H$. pratti (Turni \& Kock, 2008: 39).

\section{Material}

While working with scientific collections of the Berlin Museum of Natural History (Berlin Zoological Museum, ZMB), the author had possibility to study also the type series of Hipposideros swinhoei, collected by Peters in Amoy, China. It consists of five specimens: holotype ZMB 3996 (female, skin and skull; see Pohle, 1943; Turni \& Kock, 2008) and four paratypes (ZMB 3946 female, skull; ZMB 3947 sex unknown, skull; ZMB 3995 female, skin and skull; ZMB 3997 male, skull). I compared them with 31 specimens (skins or alcohol preserved bodies with extracted skulls) of Hipposideros from the "armiger" and "pratti" species groups, housed in ZMB, Zoological Museum of Moscow University (ZMMU), British Museum of Natural History (MNH), National Museum of Natural History in Paris (MNHN), and Natural History Museum of Geneva (MHNG):

H. armiger: China: ZMB 43280, sex unknown; ZMB 43281, sex unknown; ZMB 43282, sex unknown; ZMB 4328, female; ZMB 43285, sex unknown; ZMB 4490, male; MNHN CG1983-1967, sex unknown. Laos: MNHN CG1948-361, male (holotype of $H$. armiger tranninhensis). North Vietnam: ZMMU S-192858, female; ZMMU S-192859, female; ZMMU S-192860, female. Central Vietnam: ZMMU S-167152, male; ZMMU S-167155, male; ZMMU S-167169, male; ZMMU S-167563, male. Thailand: MNHN CG19911516, male; MNHN CG1991-1517, female; MNHN CG1991-1518, male.

H. cf. griffini: South Vietnam: ZMMU S-191905, male; ZMMU S-191906, male; ZMMU S-175145, female.

H. pratti: China: ZMB 31803, male; ZMB 43286, male; ZMB 43290, male; MNH 91.5.11.1, female (holotype of $H$. pratti); MHNG 821.76, female.
H. lylei: Thailand: MNH 13.4.18.3, male (holotype of H. lylei).

H. scutinares: Central Vietnam: ZMMU S-167163, female; ZMMU S-167164, female; ZMMU S-167168, male; ZMMU S-167176, male.

\section{Discussion}

Members of " $H$. armiger" and " $H$. pratti" complexes are quite similar in overall size, general proportions and skull measurements. They can be reliably distinguished by shape of nasal structures, more narrow and rectangular in $H$. armiger, with four pairs of lateral leaflets; and more rounded and wide in $H$. pratti and relatives, with two pairs of proportionally large lateral leaflets and - in case of males - with large transverse lobes behind the nasal leafs. Another good diagnostic feature is the skull lateral profile, evenly sloped in frontal part in $H$. armiger and concaved in $H$. pratti complex (Tate, 1941; Hill, 1963; Kruskop, 2013).

It is well seen that skulls in two of five specimens in the type series - holotype ZMB 3996 and paratype ZMB 3947 - undoubtedly demonstrate clear features of the " $H$. pratti" species group (Fig. 1). On dry skin of the holotype transverse lobes cannot be seen, because the specimen is female, but nasal leafs definitely possess shape characteristic for $H$. pratti: somewhat rounded anterior leaf with single medial notch and two pairs of supplementary leaflets. Three other paratypes belong to $H$. armiger.

This situation can be described as a taxonomic "blind spot." Noticeable, that three Chinese specimens of $H$. pratti in ZMB collection, originated from Kuangtung (? = Guangdong), China, were originally labeled as "Hipposideros swinhoei". On the original label of the ZMB 3996 the name pratti was wrote, probably by Pohle's hand. Nonetheless, nobody paid attention to these facts in last seven decades.

Possible explanation can be as follows. All the specimens in type series were captured in the same time in the same place. Their size similar (widths across canines in ZMB 3996, 3947, 3997, 3995, 3946 are $8.19,8.50,8.22,8.65,8.66$, respectively; upper tooth row lengths are $12.07,12.65,12.00,12.61,12.36)$ and lies within or nearby size variability of both $H$. armiger (8.01-8.81; 11.97-12.45) and H. pratti (8.06-8.79; 12.10-12.76: Robinson et al., 2003). The only male in the type series of $P$. swinhoei is $H$. armiger (ZMB 3997), so neither Peters himself nor Dobson could pay attention to the characteristic transverse lobes, because they are not well developed in females (and besides were additionally tightened on the stuffed skins). Skulls were extracted from skins presumably only in 1940s. That is why Peters and later Dobson and other researchers of the XIX century did not found differences between $H$. armiger and the new taxon, and Tate and other later authors (except for Pohle who really worked with $H$. swinhoei type) followed in general their opinion. Thus, only position of Turni and Kock (2008), who 


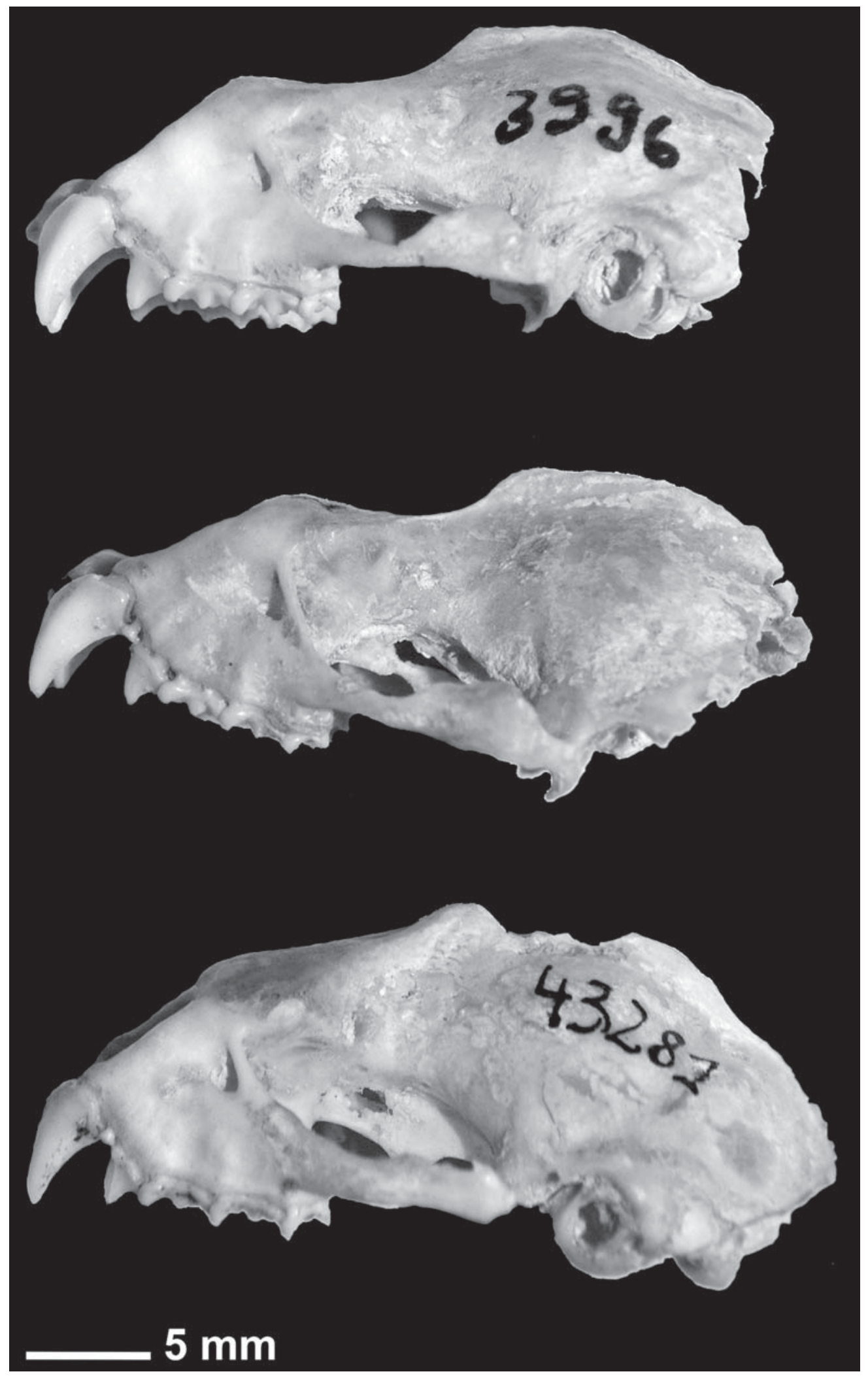

Figure 1. Lateral view on skulls of the holotype (ZMB 3996, top) and paratype (ZMB 3947, middle) of Phyllorhina swinhoei, compared with a skull of $H$. armiger (ZMB 43281, bottom) from China. 
had a possibility to view a type specimen and check its species affiliation, rises certain questions.

The type specimen of $H$. swinhoei is quite similar in size and shape to the type of $H$. pratti and has nasal leaf shape also typical to that species. According to Robinson et al. (2003) of the "H. pratti" species group only $H$. pratti itself occurs in Fujian and in the Southeast China on the whole. Though the name "pratti" was definitely used as valid species name by many authors in last 50 years, meantime the name "swinhoei" was also used as valid name after 1899 (as a subspecies of H. armiger; see Allen, 1938; Ellerman \& MorrisonScott, 1951). So, the conditions declared by ICZN for the reversal of name precedence (ICZN, 1999; see article 23.9.1) are not fully complied, and the name "swinhoei" can not be considered nomen oblitum. Thereby, H. swinhoei (Peters, 1871) should be excluded from the synonymy of $H$. armiger and regarded as a full senior synonym of $H$. pratti. In this case the whole species group should be renamed into " $H$. swinhoei" species group.

ACKNOWLEDGEMENTS. I am sincerely grateful to Dr. Frieder Mayer and Mrs. Nora Lange for access to the bat collections of the Berlin Zoological Museum and for their help and hospitality during the authors stay in Berlin; to Dr. Roberto Portela Miguez for access to the bat collection of the Museum of Natural History, London; to Dr. Manuel Ruedi for access to the collections of the Geneva Natural History Museum; and to Dr. Jean-Marc Pons for access to the collections of the National Museum of Natural History in Paris. Original material used for comparison was collected during the complex expeditions organized by Vietnamese-Russian Tropical Center under supervision of Dr. Andrei N. Kuznetzov, Dr. Nguyen Dang Hoi and Dr. Vitaly L. Trunov. Study was financially supported by Russian Foundation for Basic Research (grant No 13-04-00439a).

\section{References}

Allen G.M. 1938. The Mammals of China and Mongolia. New York: American Museum of Natural History. 620 p. Dobson G.E. 1876. Monograph of the Asiatic Chiroptera. London: Taylor \& Francis. 228 p.

Ellerman J.R. \& Morrison-Scott T.C.S. 1951. Checklist of
Palaearctic and Indian Mammals 1758 to 1946. London: British Museum (Natural History). 810 p.

Francis C.M. 2008. A field guide to the mammals of SouthEast Asia. London: New Holland. 392 p.

Francis C.M., Borisenko A.V., Ivanova N.V., Eger J.L., Lim B.K., Guillen-Servent A., Kruskop S.V., Mackie I. \& Hebert P.D. 2010. The role of DNA barcodes in understanding and conservation of mammal diversity in Southeast Asia // PLoS ONE. Vol.5. No.9. P.1-12.

Hill J.E. 1963. A revision of the genus Hipposideros // Bulletin of the British Museum of (Natural History), Zoology Series. Vol.2. P.1-129.

ICZN. 1999. International Code of Zoological Nomenclature. Fourth edition. London: International Trust for Zoological Nomenclature. $124 \mathrm{p}$.

Koopman K.F. 1994. Chiroptera: Systematics // Neithammer J., Schliemann H. \& Starck D. (eds.) Handbook of Zoology. Mammalia. Berlin \& New York: Walter de Gruyter. Vol.8. Part 60. 217 p.

Kruskop S.V. 2013. Bats of Vietnam. Checklist and an Identification Manual. Second edition, revised and supplemented. Biodiversity of Vietnam series. Moscow: Êİ̂E Scientific Press. 300 p.

Peters W.C.H. 1871. Bats submitted to W. Peters, who supplied names and descriptions of n. sp. // Swinhoe R. (ed.). Catalogue of the Mammals of China (south of the River Yangtse) and of the Island of Formosa. Proceedings of the Zoological Society of London. Vol.1870. P.615-653.

Pohle H. 1943. Die Originale der Peters'schen Beschreibung Chinesischer Fledertiere 1870 // Zeitschrift für Säugetierkunde. Vol.15. P.321-323.

Robinson M.F., Jenkins P.D., Francis C.M. \& Fulford A.J.C. 2003. A new species of the Hipposideros pratti group (Chiroptera, Hipposideridae) from Lao PDR and Vietnam // Acta Chiropterologica. Vol.5. No.1. P.31-48.

Simmons N.B. 2005. Order Chiroptera // Wilson D.E. \& Reeder D.M. (eds.). Mammal Species of the World. A Taxonomic and Geographic Reference. Third edition. Baltimore: Johns Hopkins University Press. Vol.1. P.312529.

Tate G.H.H. 1941. A review of the genus Hipposideros with special reference to Indo-Australian species // Bulletin of the American Museum of Natural History. Vol.78. Art.5. P.353-393.

Turni H. \& Kock D. 2008. Type specimens of bats (Chiroptera: Mammalia) in the collections of the Museum für Naturkunde, Berlin // Zootaxa. No.1869. P.1-82. 